\title{
ADMINISTRATIE EN ORGANISATIE
}

\author{
door Prof. R. W. Starreveld
}

In aansluiting op de artikelen in het februari- en meinummer van dit blad, waarin eerst een poging werd gedaan om tot een verantwoorde afgrenzing van het begrip ,administratie" te geraken om vervolgens aandacht te schenken aan de gang van de ontwikkeling, welke de administratie in de loop der eeuwen heeft doorgemaakt en ook nu nog bezig is door te maken, willen wij thans nagaan, welke consequenties de daarbij verkregen inzichten hebben m.b.t. de problematiek van de interne bedrijfsorganisatie.

De aanrakingspunten tussen administratie en organisatie zijn vele en velerlei. Het zal niet mogelijk zijn die alle in het bestek van een enkel artikel recht te doen wedervaren. Wij zullen ons daarom tot enkele hoofdpunten moeten beperken.

Achtereenvolgens zullen wij aandacht schenken aan

- de betekenis van een goede administratie voor de interne bedrijfsorganisatie;

- de betekenis van een goede interne bedrijfsorganisatie voor de administratie;

- de plaats van de administratie in het geheel van de interne organisatie van het bedrijf;

- de invloed van de verschijning van universele informatieverwerkingsmachines;

- enkele consequenties voor de praktiserende accountant.

\section{De betekenis van een goede administratie voor de interne bedrijfsorganisatie}

Wie het beeld van de administratie, dat in de vorige artikelen geschetst is, op zich laat inwerken, zal niet kunnen ontkomen aan de conclusie dat ",administratie” bezig is zich te ontplooien tot iets waarvan de betekenis verre uitgaat boven die van de administratie van weleer, welke zich in hoofdzaak beperkte tot het doen kennen van grootte en samenstelling van kapitaal en vermogen en van de mutaties welke daarin optreden. De bekende uitdrukking dat de administratie zich ontwikkelt tot ,a tool of management" typeert die verandering slechts onvolkomen; zeker indien men met "management" in het bijzonder de hoogste leiding op het oog heeft. Het nieuwe administratiebegrip grijpt veel verder en inspireert tot een geheel andere beeldspraak, waarbij de administratie wordt gezien als een volledig zenuwstelsel, dat niet alleen het centrale, doch ook het z.g. periphere zenuwstelsel omvat, dat zich tot de uiterste geledingen van de organisatie uitstrekt. Het laatste is in hoofdzaak gericht op de communicatie, terwijl het eerste dient voor de coördinatie, veredeling en bewaring van de ontvangen informatie. De analogie met het zenuwstelsel van een levend organisme gaat overigens in zoverre niet op, dat de verrichtingen van een organisatie niet uitsluitend via de administratie worden bestuurd en beheerst. Rechtstreekse zintuigelijke waarneming, intuïtieve oordeelsvorming en mondelinge communicatie zullen immers daarnaast altijd een belangrijke rol blijven spelen. Doch ook met die beperking blijft een goede administratie een stelsel dat ten nauwste met de gehele organisatie verweven is en welks inrichting en werking vooral bij grote en gecompliceerde organisaties van eminente betekenis is voor de goede functionering van het geheel.

Een belangrijk deel van de op verhoging van de efficiency gerichte organisatorische maatregelen bestaat uit vastlegging, systematisering, samenvatting en overbrenging van informatie. Goed organiseren is praktisch onmogelijk zonder dat 
daarbij allerlei administratieve maatregelen worden genomen. Voorzover organiseren gericht is op economisch handelen, nemen snelle en betrouwbare informatie omtrent situaties, behoeften, mogelijkheden e.d., systematische af weging van nut en kosten, alsmede snelle en betrouwbare communicatie tussen de in arbeidsverdeling samenwerkende functionarissen daarbij een uiterst belangrijke plaats in.

De intense verbondenheid van administratie en organisatie impliceert dat het niet verantwoord is, de administratie als een „Ding an sich" te ontwerpen. Het ontwerp dient voort te vloeien uit een diepgaande analyse van de economische, organisatorische en operationele problematiek van alle onderdelen van het betrokken bedrijf. Die analyse dient een inzicht te geven in:

- de punten waaromtrent de onderscheiden functionarissen op verschillend hiërarchisch niveau op grond van de hun opgedragen taken en verleende bevoegdheden beslissingen moeten nemen;

- de controleverplichtingen die de onderscheidene hogere en lagere leidinggevende functionarissen hebben op grond van de door hen gedelegeerde bevoegdheden;

- de elementen, regels en overwegingen welke bij het nemen van deze beslissingen en het uitvoeren van deze controle een rol (moeten) spelen;

- de informatie welke genoemde functionarissen op grond daarvan nodig hebben;

- de betekenis welke moet worden toegekend aan de mate van betrouwbaarheid en nauwkeurigheid van die informatie, de grootte van het informatie-interval en de snelheid van berichtgeving;

- de communicatiebehoeften, welke uit een en ander voortvloeien.

Bij het verrichten van een dergelijk onderzoek zal het dikwijls doelmatig blijken, de structuur van de taakverdeling en de daarbij behorende samenwerkingsprocedures niet zonder meer als gegeven te beschouwen, doch ook deze aan een kritische beschouwing te onderwerpen. Het heeft immers weinig zin om een informatiestelsel te ontwikkelen op basis van een ondoelmatig gestructureerde werkverdeling en/of inefficiënte werkprocedures.

Indien de administratieve deskundigen welke een dergelijk systeem ontwerpen, niet een brede algemeen-organisatorische kennis en ervaring hebben, zullen zij daarom bij een enigszins diepgaande reorganisatie de bijstand behoeven van anderen die wel daarover beschikken. ${ }^{1}$ )

Omgekeerd zal een programma tot verbetering van een onvoldoende organisatie in den regel weinig uitzicht op een goed resultaat bieden, wanneer daarin niet een belangrijke plaats is ingeruimd voor de ontwikkeling van een goed administratiesysteem dat in beginsel het gehele in de vorige artikelen geschetste gebied dekt. Zonder zulk een systeem mist men immers, althans in een bedrijf van enige omvang, de basis voor het nemen van optimale beslissingen zowel als voor het uitoefenen van een zo effectief mogelijke controle, terwijl ook de communicatie de nodige snelheid, exactheid en betrouwbaarheid zal ontberen. Wat komt er bij bedrijven met een onvoldoend administratiesysteem terecht van belangrijke organisatorische maatregelen als het invoeren van budgettering, planning, werk-

1) Uiteraard is voor het vaststellen van de informatiebehoeften die zich in een concrete situatie voordoen, naast organisatorische kennis ook algemene bedrijfseconomische kennis van betekenis. In dit artikel zullen wij onze aandacht echter in het bijzonder richten op de samenhang tussen administratie en organisatie. 
voorbereiding en voortgangscontrole? Een goede administratie is bij die alle een onmisbaar complement. Een organisator die de specifieke deskundigheid voor het ontwerpen van zulk een administratie mist, verzekere zich daarom de bijstand van een administratief deskundige.

\section{De betekenis van een goede interne bedrijfsorganisatie voor de administratie}

De aanwezigheid van een goede interne bedrijfsorganisatic is in meer dan één opzicht voorwaarde voor een doelmatig functioneren van de administratie.

Een van de eerste vereisten voor een betrouwbare administratie is, dat in het bedrijf orde en tucht heersen. Waar wanorde heerst heeft men geen waarborgen voor de juistheid en volledigheid der primaire aantekeningen. Naarmate er meer geordend is, neemt de betrouwbaarheid der gegevens toe.

Voorbeelden:

- De zekerheid omtrent de volledigheid van de registratie der verplichtingen wordt vergroot door de bevoegdheid tot het aangaan van verplichtingen te beperken tot bepaalde personen.

- Een goede verbruiksregistratie wordt bevorderd door de grondstoffen in een afgesloten magazijn te doen bewaren.

- Bij produktie op voorraad wordt de betrouwbaarheid van de produktieregistratie verhoogd door een speciale instantie aan te wijzen voor het in ontvangst nemen, bewaren en afgeven der produkten.

- Een goede registratie der vorderingen wordt bevorderd door de bevoegdheid tot het verzenden van goederen en facturen te beperken tot bepaalde functionarissen.

- De toerekening van kosten aan de verschillende kostenplaatsen zal beter geschieden naarmate de taken en bevoegdheden van de betrokken afdelingschefs scherper zijn afgebakend en deze functionarissen meer uitdrukkelijk voor de kosten en prestaties hunner af delingen verantwoordelijk worden gesteld; zij zullen alsdan meer aandacht besteden aan het voorafgaand fiatteren van te hunnen laste komende kosten.

Verder kan men stellen dat de waarde van een administratie, afgezien van haar betekenis als communicatiemiddel, in hoofdzaak wordt bepaald door wat men met de door haar verschafte informatie kan doen.

a) als grondslag voor beslissingen (handelingenkeuze)

b) als grondslag voor het uitoefenen van controle (kritische oordeelsvorming achteraf) ${ }^{2}$ ).

In een concrete situatie is die waarde derhalve in belangrijke mate afhankelijk van de praktische mogelijkheden die bij de gegeven organisatie aanwezig zijn om deze informatie daadwerkelijk dienstbaar te maken aan het nemen van doelmatige beslissingen en het uitoefenen van een effectieve controle.

De mogelijkheden tot het gebruik van de door de administratie verschafte in-

2) Hier wordt niet in de eerste plaats gedacht aan accountantscontrole, noch aan controle in de beperkte zin van verificatie van de juistheid van bepaalde informatie. Onder controle wordt hier verstaan iedere kritische oordeelsvorming achteraf omtrent een toestand of gebeuren zelve, dan wel omtrent de juistheid van de daarover verstrekte informatie. 
formatie als grondslag voor het nemen van beslissingen zijn o.m. afhankelijk van de mate van delegatie van beslissingsbevoegdheden. Wanneer de hoogste leiding onvoldoende delegeert, zal deze spoedig verdrinken in de veelheid van cijfers die de administratie verschaft, met het gevolg dat het cijfermateriaal onvoldoende produktief wordt gemaakt.

De bruikbaarheid van de door de administratie verschafte informatie voor het uitoefenen van controle op de verschillende bedrijfsfunctionarissen die belast zijn met het nemen van beslissingen, met het uitvoeren der bedrijfshandelingen of met het bewaren van waarden is o.m. afhankelijk van de waarborgen die zijn gelegen in de structuur van de taakverdeling en de daarbij toegepaste functiescheiding.

Voor het uitoefenen van controle heeft men verder behoefte aan kosten-, prestatie-, rendements- en kwaliteitsnormen, die overigens ook reeds bij het nemen van beslissingen een belangrijke rol kunnen spelen. De effectiviteit van de controle is o.m. afhankelijk van de toleranties in die normen en van de grootte van de kans op overschrijding dier toleranties door toevallige omstandigheden. De controlemogelijkheden zijn maximaal in een bedrijf waar willekeur en toeval tot een minimum beperkt zijn. Dat is zo wanneer

- voor alles zo veel mogelijk een vaste, systematisch gekozen plaats, tijd en handelwijze is voorgeschreven;

- de produlktiemiddelen, arbeidsmethoden en arbeidsomstandigheden zo veel mogeliik genormaliseerd zijn (standard conditions);

- voor een goede planning en werkvoorbereiding gezorgd wordt (op het moment dat de uitvoerende arbeid een aanvang neemt, moet alles zodanig geregeld zijn, dat het werk overeenkomstig de an de voorcalculatie ten grondslag liggende veronderstellingen kan verlopen).

Controle is overigens in den regel alleen dan maximaal effectief wanneer

(a) de verantwoordelijkheid der verschillende functionarissen voor de onderscheiden kosten, prestaties en opbrengsten scherp afgebakend is

(b) de bij de controle afzonderlijk beschouwde organisatie-onderdelen zoveel mogelijk homogene taken hebben, in dien zin dat de omvang der prestaties ten behoeve van de controle zonder bezwaar in één enkele rekengrootheid kan worden uitgedrukt

(c) meetbare en onmeetbare prestaties zoveel mogelijk organisatorisch gescheiden worden gehouden

(d) naast de kwantitatieve normen ook kwalitatieve normen zijn vastgesteld, aan de hand waarvan kwaliteitscontrole wordt uitgeoefend, daar anders de controle op de $\mathrm{kwantiteiten}$ veelal tot vermindering van de $\mathrm{kwaliteit}$ leidt.

Ook hier blijkt dat het in het algemeen niet doelmatig is een verbetering van de administratie ter hand te nemen zonder tevens aandacht aan de verdere organisatie te schenken. Dit zal zich sterker doen gevoelen naarmate tengevolge van de voortschrijdende ontwikkeling van wetenschap, techniek en verkeer hogere eisen aan administratie en organisatie worden gesteld en beide sterker op elkaar betrokken raken.

Voor hen die het accountantsberoep uitoefenen, betekent dit, naar zich laat aanzien, dat zij in de toekomst òfwel zich zullen moeten beperken tot het verrichten van controle en in aansluiting daarop het aangeven van de eisen, welke ten be- 
hoeve van die controle aan de inrichting van de administratie moeten worden gesteld, of wel de gehele bedrijfsorganisatorische problematiek in hun beschouwingen moeten betrekken. Halt houden bij de grenzen van de administratie zal in vele gevallen een ondoelmatige afbakening van hun bemoeienissen blijken. Besluit de accountant ertoe zijn activiteiten tot de gehele interne organisatie uit te strekken, dan zal hij er echter voor moeten zorgen dat zijn kennis en ervaring op dit gebied geen ernstige hiaten vertoont. Op bepaalde onderdelen, met name wat betreft de technische details, zal hij zich uiteraard moeten doen bijstaan door op die onderdelen gespecialiseerde deskundigen.

\section{De plaats van de administratie in het gebeel van de interne organisatie van het bedrijf}

Reeds in de aanvang van het eerste artikel van deze serie (,Wat is administratie?”, febr. 1961), merkten wij op dat de afgrenzing van het begrip ,administratie” niet mag prejudiceren t.a.v. de vraag aan wie leiding en uitvoering van de administratieve arbeid nioeten worden opgedragen. Verruiming van het administratiebegrip mag dus niet automatisch leiden tot uitbreiding van de zeggenschap van hen die tot dusver met de zorg voor de administratie of althans met een belangrijk deel daarvan belast zijn. Reeds m.b.t. administraties met een uiterst beperkte doelstelling kan men zich afvragen of het wel verstandig is het beleid t.a.v. inrichting en functioneren van de administratie geheel over te laten aan het hoofd van de administratic en aan de administratieve deskundigen. Zulks geldt a fortiori voor administratieve complexen welke onder de in de vorige artikelen besproken ruime definitie vallen. Het zou hoogst bedenkelijk zijn initiatief en beslissing omtrent de concrete doelstellingen waarop zulk een complex moet worden gericht, alsmede omtrent de wijze waarop het zal worden ingericht en zal functioneren, te beschouwen als zaken die uitsluitend de administrateur en de administratieve deskundigen zouden aangaan. Daarvoor raakt de administratie in zijn ontwikkelde vorm te zeer de vitale belangen van alle onderdelen van het bedrijf en speelt zij een te belangrijke rol in de taakvervulling van alle beleidvoerende, controlerende en toezichthoudende functionarissen. Elk dezer functionarissen zal in beginsel zijn bijdrage moeten leveren bij de opstelling van het administratieprogramma. Hij zal daarbij in zekere zin als staffunctionaris moeten fungeren, die aangeeft, waar nodig met bijstand van een theoretisch geschoolde bedrijfseconoom, omtrent welke punten, zijn sector betreffende, regelmatig informatie gewenst is ten behoeve van de beleidvoering en/of de beheersing der bedrijfsoperaties. De totaliteit van het administratieve systeem zal moeten worden geboren uit de samenwerking van velen. De administratieve deskundigen zullen daarbij de taak hebben een systeem te ontwerpen waarmee een optimale bevrediging van de totaliteit der door de verschillende functionarissen naar voren gebrachte wensen kan worden bereikt. De centrale conceptie van het systeem behoeft echter niet in te houden dat ook de uitvoering van de administratie wordt gecentraliseerd, zomin dat deze bij gedecentraliseerde uitvoering per se onder een centrale leiding zou moeten worden geplaatst. Geval voor geval zal men de voor- en nadelen van de verschillende mogelijkheden van taakverdeling en van de verschillende varianten in de mate van zeggenschap m.b.t. de verschillende onderdelen van de administratie tegenover elkaar moeten afwegen. Het gaat hierbij om organisatieproblemen die niet met de toepassing van enkele eenvoudige schemata kunnen worden afgedaan. Zeker niet wanneer men 
bedenkt dat hier volop stof voor prestigekwesties, spanningen en conflicten ligt. Belangen en mogelijkheden van interne controle zullen daarbij o.m. moeten worden afgewogen tegen belangen en mogelijkheden van snelle en op de behoeften afgestemde informatie aan beleidvoerende, controlerende en toezichthoudende functionarissen op alle niveaus van de hiërarchie terwijl ook de eventuele mogelijkheden tot kostenbesparing welke centralisatie van de administratie zou bieden in de afweging dienen te worden betrokken. Uiteraard hebben de administrateur en de administratieve deskundigen bij die af weging een belangrijke stem, doch men hoede zich hierbij voor overdrijving; de actieve medewerking van andere deskundigen die de technische, commerciële en organisatorische problematiek van de verschillende bedrijfsonderdelen kennen is van minstens evenveel belang. Met betrekking tot het opstellen van het administratieplan dient daarom "samenwerking" of - zo men wil - ,teamwork" het wachtwoord te zijn.

Dit alles neemt niet weg, dat er wat de uitvoering betreft een aantal argumenten kunnen worden aangevoerd voor het onderbrengen van bepaalde gedeelten van de administratie bij een afzonderlijk orgaan. De belangrijkste van die argumenten zijn:

1. Uit een oogpunt van interne controle is het gewenst, de registraties aan de hand waarvan de controle op beheerders, uitvoerders en bewaarders wordt uitgeoefend, te doen geschieden door personen die hiërarchisch en maatschappelijk onafhankelijk zijn van de te controleren functionarissen. Dat geldt niet alleen voor de uitvoering van die registraties, doch ook voor de leiding daarvan. De hoogste leider van het administratieve apparaat dient daarom bij voorkeur direct onder de topleider van het gehele bedrijf te staan, opdat hij zoveel mogelijk vrij sta van de afzonderlijke beheerders en bewaarders. (Doordat hij echter nimmer vrij kan staan van de hoogste leider, blijft zijn onafhankelijkheid altijd een betrekkelijke.)

2. Het doen verrichten van administratieve arbeid door speciaal daarvoor geschikt personeel biedt in den regel kostenvoordelen. Zulks o.m. omdat voor het verrichten van de hoger gekwalificeerde administratieve arbeid speciale deskundigheid nodig is, terwijl de lager gekwalificeerde arbeid speciale aanleg en vaardigheid vereist. Onderbrenging van deze arbeid in een centraal orgaan schept gewoonlijk gunstiger kwantitatieve verhoudingen.

3. Onderbrengen van de administratie in een centraal orgaan biedt de mogelijkheid een gemeenschappelijke administratie te voeren voor verschillende doeleinden en voor verschillende belanghebbende functionarissen of afdelingen. Daardoor kan niet alleen wat betreft de verwerking van de gegevens, maar ook wat betreft het verstrekken van het grondmateriaal (primaire aantekeningen) duplicering worden voorkomen.

4. Het onderbrengen bij een centraal orgaan biedt de mogelijkheid tot het scheppen en hanteren van allerlei controleverbanden tussen de verschillende onderdelen van de administratie; de betrouwbaarheid van de daaraan ontleende gegevens wordt daardoor vergroot. Bovendien biedt centralisatie grotere mogelijkheden tot het verstrekken van allerlei complementaire informatie die van betekenis kan zijn voor hen die informatie nodig hebben als basis voor het nemen van beslissingen. 
5. Bundeling van administratieve werkzaamheden in een centrale afdeling vergroor de mogelijkheden tot het economisch gebruik van administratiemachines. Tegenover deze voordelen van het onderbrengen van de administratie in een afzonderlijk orgaan staan de volgende nadelen:

1. Er ontstaat een tweevoudig communicatieprobleem doordat:

a) zij die de administratie voeren de daarvoor benodigde grondgegevens niet meer rechtstreeks door eigen waarneming kunnen verkrijgen;

b) de door de administratie te verschaffen gegevens niet meer in handen zijn van degenen die die gegevens moeten gebruiken.

Het voorzien in deze communicatiebehoefte vraagt in den regel niet alleen extra arbeid, doch vermindert, voorzover er niet van speciale communicatietechnieken gebruik wordt gemaakt, gewoonlijk ook de snelheid waarmee incidenteel benodigde informatie kan worden verstrekt.

2. Zij die belast zijn met het voeren van de administratie komen verder van het eigenlijke bedrijf af te staan en kunnen daardoor minder goed beoordelen welke eisen aan hun werk worden gesteld en wat de reeële betekenis is van hetgeen zij registreren.

3. Een aldus gevoerde administratie kan niet meer als eigen verantwoording van de betrokken beheerders, bewaarders of uitvoerders worden beschouwd. De juistheid van de door de administratie verstrekte gegevens kan daarom door deze functionarissen worden betwist, waardoor het verantwoordelijk stellen voor eventuele tekorten of minder gunstige uitkomsten in het gedrang kan komen.

Naarmate de nadelen zich sterker doen gevoelen, zal er een sterkere tendenz tot decentralisatie van de administratie optreden, waarbij zich dan echter weer het wegvallen van de voordelen van centralisatie voelbaar maakt. Waar in een concrete situatie het juiste midden is gelegen, zal in belangrijke mate afhangen van de structuur van de leiding in het betrokken bedrijf en in het bijzonder van de mate waarin het nemen van beslissingen is gecentraliseerd of gedecentraliseerd. Ook hier zien wij dus weer een samenhang tussen administratie en organisatie, c.q. tussen administratieve organisatie en algemene organisatie, zij het dat die samenhangt, wat het communicatie-aspekt betreft, sterk kan worden verminderd door toepassing van geëigende telecommunicatie-technieken.

Overigens zijn er uiteraard allerlei mengvormen mogelijk. Zo kan men b.v. zijn toevlucht nemen tot het volgende compromis:

De administratie bij de betrokken beheerder(s), bewaarder(s) of uitvoerder(s) doen bijhouden door een administratieve functionaris die te hunner beschikking is gesteld, doch die functionele bindingen heeft met de leider van de administratie welke hem bindende aanwijzingen kan verstrekken m.b.t. de inhoud van de administratie en van de rapportering, alsmede wat betreft de wijze waarop deze dienen te worden samengesteld.

Deze oplossing schiet echter tekort wanneer het om bijzonder kostbare goederen of waardepapieren gaat. Het is dan n.l. van belang dat daarvan enerzijds een administratie wordt gevoerd die gebeel buiten de directe of indirecte invloed van de betrokken beheerder of bewaarder wordt gehouden, en anderzijds één die voortdurend te zijner beschikking staat, zowel om zich regelmatig er van te 
kunnen overtuigen of de aan hem toevertrouwde waarden alle nog aanwezig zijn, als om zich te kunnen vrijwaren tegen schijntekorten voortvloeiende uit fouten in de buiten hem om gevoerde administratie. Een z.g. contra-administratie of „doublure" is dan alleszins verantwoord.

Indien een dergelijke doublure niet noodzakelijk wordt geoordeeld en anderzijds de waarborgen, gelegen in een functionele binding van het betrokken administratief personeel aan de centrale leider van de administratie, onvoldoende worden geacht, kan de oplossing ook worden gezocht in decentralisatie van de administratie met behoud van een zuivere lijnstructuur, waarbij dus het administratief personeel uitsluitend ondergeschikt is aan functionarissen behorende tot de administratieve hiërarchie.

De binding van het betrokken personeel aan de centrale leider van de administratie is dan weliswaar sterker dan wanneer er alleen een functionele band is, doch alleen bij een betrekkelijk grote administratie met een krachtige centrale leiding kan in een dergelijke situatie worden bereikt dat de locale administratieve functionarissen werkelijk onafhankelijk van de overige plaatselijke functionarissen blijven.

Het belangrijkste voordeel van een dergelijke zuiver ruimtelijke decentralisatie van de administratie is de verkorting van de communicatielijnen met het bedrijf. Zowel het verkrijgen van de grondgegevens van de onderscheiden bedrijfsafdelingen als het verschaffen van de uiteindelijke informatie aan deze afdelingen wordt daardoor vereenvoudigd en versneld.

Verder betekent de grotere locale kennis waarover de plaatselijke administratie beschikt in vele gevallen een voordeel.

Als nadeel staat daar dikwijls tegenover, dat de $\mathrm{kwantitatieve} \mathrm{verhoudingen}$ minder gunstig worden door verkleining van de massa; met name de mogelijkheden tot gebruikmaking van machines worden daardoor verkleind. In het bijzonder geldt dat bij het gebruik van zeer gespecialiseerde (c.q. gedifferentieerde) machines en van machines met grote capaciteit.

\section{De invloed van de verschijning van universele informatieverwerkingsmachines}

De omstandigheid dat elektronische informatieverwerkingsmachines een welhaast universele toepasbaarheid hebben voor de meest uiteenlopende informatieverwerkingsproblemen, heeft ertoe geleid dat de belangstelling voor deze machines geenszins beperkt is gebleven tot de kringen van hen die zich tot nog toe met de administratie plachten bezig te houden. Ingenieurs, chemici, wiskundigen, economen, statistici, actuarissen en tal van andere groepen van deskundigen zien plotseling geheel nieuwe mogelijkheden voor de oplossing van hun problemen opdoemen. Bij velen van hen doet dit de wens opkomen die mogelijkheden intensief te exploreren, hetgeen bij de betrokkenen het verlangen doet ontstaan om niet alleen méér over deze apparaturen te weten te komen doch ook om zo mogelijk zelf de beschikking over een dergelijke installatie te verkrijgen. Zodra blijkt dat ook andere functionarissen dezelfde ambities hebben, ontstaat reeds spoedig een strijd om de hegemonie m.b.t. de elektronische informatieverwerking. Velen zijn daarbij geneigd de eigen problematiek en de eigen deskundigheid als de belangrijkste te zien en die van de anderen te bagatelliseren. Beseffend dat de hoge kosten van elektronische machines het gebruik maken van een gemeenschappelijke apparatuur

m a b blz. 209 
welhaast dwingend voorschrijven, verklaart men zich alras om strijd bereid de verschillende werkzaamheden die de andere functionarissen zo belangrijk vinden ,er wel even bij te doen" mits men zelf het hoofdsysteem, of althans datgene wat men zelf als zodanig beschouwt, mag ontwikkelen en zelf de daarbij te gebruiken apparatuur mag hanteren. Een belangrijke rol speelt daarbij ongetwijfeld ook de omstandigheid dat de kostbare en in zeker opzicht magische "computer" als statussymbool gaat fungeren voor hen die er mee mogen werken. Reeds heel veel competentiestrijd is op grond daarvan rondom de „computer" geleverd. Voor zover het daarbij gaat om de alleenbeerschappij, is zulk een strijd in den regel volkomen heilloos. Men zal in deze moeten samenwerken en zich moeten zetten tot een gecoördineerd collectief denken over de aan de orde zijnde problemen, waarbij ieder op grond van eigen specifieke deskundigheid cen bepaalde bijdrage kan leveren. Dat deskundigheid op de gebieden van bedrijfseconomie, organisatie, administratie en administratieve techniek daarbij een belangrijke rol zal spelen behoeft geen betoog. Maar dat betekent allerminst dat daarnevens niet ook de medewerking van functionarissen met technische, commerciële en andere deskundigheden van grote betekenis zou zijn. Bundeling van al die deskundigheden in commissies en werkgroepen voor het opstellen van richtlijnen en het uitwerken van plannen is in dergelijke gevallen in hoge mate wenselijk.

Indien de aldus ontwikkelde plannen uiteindelijk tot het aanschaffen van een elektronische apparatuur leiden, zal het veelal gewenst blijken het bebeer van die apparatuur in handen te leggen van personen die volkomen neutraal tegenover de verschillende belanghebbenden staan, opdat hun belangen objectief tegenover elkaar kunnen worden afgewogen, dan wel volgens van hogerhand daarvoor vastgestelde richtlijnen kunnen worden behartigd. Ook de omstandigheid dat een groot deel van de verwerkte informatie tevens dienst doet voor het uitoefenen van controle op de bewaring van waarden, op het gebruik dat van gedelegeerde bevoegdheden wordt gemaakt e.d., maakt het gewenst de desbetreffende informatieverwerking alsmede de bewaring van de betrokken informatieverzamelingen onafhankelijk van de te controleren functionarissen te doen plaatsvinden.

Terwijl dus het informatiebeleid alsmede de keuze van de werkwijze met betrekking tot de informatieverwerking en informatieverstrekking in de eerste plaats een kwestie van samenwerking en overleg is, dient het bebeer van de apparatuur en de bewaring van de informatieverzamelingen juist buiten het algemene krachtenveld te worden gehouden en in neutrale handen te worden gelegd.

\section{Enkele consequenties voor de praktiserende accountant}

Het is wellicht nuttig de consequenties, welke uit de in het voorafgaande gegeven beschouwingen voor de praktiserende accountant voortvloeien, in het kort samen te vatten en daaraan dan nog enkele aanvullende opmerkingen toe te voegen.

Wij zagen dat administratie en organisatie tegenwoordig een zodanige samenhang vertonen dat

- een accountant die wordt geroepen advies uit te brengen omtrent de inrichting van de administratie van een bedrijf zich zal moeten verdiepen in de totale organisatorische problematiek van dat bedrijf en dat hij daarom, indien hij zelf m.b.t. die problematiek niet voldoende deskundig is, de bijstand zal moeten inroepen van iemand die dat wel is; 
- een organisatiedeskundige die wordt geroepen advies uit te brengen omtrent de verbetering van de organisatie van een bedrijf, in zodanige mate geconfronteerd wordt met administratieve vraagstukken dat hij, zo hij zelf m.b.t. die vraagstukken onvoldoende deskundig is, de bijstand zal moeten inroepen van een accountant.

Reeds hieruit kan tot op zekere hoogte de wenselijkheid van de vereniging van beide deskundigheden in eenzelfde persoon of althans in eenzelfde kantoor worden afgeleid.

In ieder geval meenden wij op grond daarvan te mogen stellen dat de accountant in de toekomst wellicht meer en meer zal moeten kiezen tussen:

- beperking tot de controle-praktijk en overlaten van de gehele organisatie met inbegrip van de administratieve organisatie aan anderen die op dat gebied deskundig zijn en die door hem worden ingelicht omtrent zijn desiderata m.b.t. de interne controle;

- combinatie van de controle-praktijk met de algemene organisatie adviespraktijk, waarbij alleen voor details die een bijzondere technische deskundigheid vereisen, wordt teruggevallen op de medewerking van anderen.

Het zou ons te ver voeren, indien wij zouden trachten hier alle aspecten van dit alternatief te belichten. Zulks zou wellicht zelfs meer dan een enkel tijdschriftartikel vereisen.

Hier zij daarom volstaan met een drietal opmerkingen:

1) Tegen de keuze van de eerste mogelijkheid pleit dat de accountant daardoor als controleur in een ongunstige positie wordt geplaatst doordat hij afstand doet van de mogelijkheid zelf de wegen aan te geven om op economisch verantwoorde wijze te voldoen aan de door hem aan de administratie gestelde eisen.

2) Voor de keuze van de tweede mogelijkheid pleit o.m. de omstandigheid dat een intensieve bemoeienis met de organisatie van het bedrijf ook van grote betekenis is voor de door de accountant uit te oefenen controle op administratie en verantwoordingsstukken. Een dergelijke bemoeienis biedt hem o.m. de mogelijkheid zich een oordeel te vormen omtrent de betekenis die mag worden toegekend aan kosten-, prestatie-, kwaliteits- en rendementsnormen. Daar die normen niet alleen bij de interne controle doch ook bij de accountantscontrole vaak een welhaast beslissende rol spelen en de effectiviteit van de controle o.m. afhankelijk is van de toleranties in die normen en van de grootte van de kans op overschrijding dier toleranties ten gevolge van toevallige omstandigheden, heeft de accountant er in hoge mate belang bij, dat in het gecontroleerde bedrijf zodanige toestanden en verhoudingen worden geschapen, dat willekeur en toeval door een goede organisatie tot een minimum worden beperkt, zodat normen met nauwe toleranties kunnen worden opgesteld.

Ook de omstandigheid dat de voor het organisatie-onderzoek vereiste nauwgezette waarneming van het bedrijf en zijn functionering grote betekenis heeft voor de vorming van een oordeel omtrent de aanvaardbaarheid van voorgelegde verantwoordingscijfers, pleit voor het combineren van de functies van organisatie-adviseur en controleur.

3) Wie zijn keuze op de tweede mogelijkheid bepaalt, verplicht zich tot een na-

m a b blz. 211 
dere theoretische en praktische bezinning op de algemene organisatorische problematiek. Die problematiek heeft namelijk nog andere aspecten dan die welke wij bij onze studie van de bedrijfseconomie hebben leren kennen. Ten onrechte wordt in onze kring wel eens simpelweg gesteld dat ,de" leer van de organisatie zonder meer een onderdeel van de bedrijfseconomie zou zijn. De bedrijfseconomie onderzoekt uiteraard slechts de bedrijfseconomische aspecten van de organisatieproblematiek en beschouwt alle andere aspecten als „data”. Het zal geen betoog behoeven dat wie zich als adviseur met praktische organisatievraagstukken gaat bezighouden, zich een dergelijke vereenvoudiging van de problematiek niet wel kan veroorloven. Hij zal het daarom niet kunnen stellen zonder enig begrip van de meest voorkomende situatie- en gedragspatronen welke zich in de praktijk van het bedrijfsleven voordoen en van de verschillende krachten welke daarop hun invloed doen gelden. Zijn succes als adviseur zal zelfs in belangrijke mate afhankelijk zijn van de rijkdom aan kennis, ervaring en inzicht die hij zich in de loop der jaren met betrekking tot het gedrag dier ,data” heeft weten te verwerven. Dat neemt niet weg, dat een grondige kennis van de bedrijfseconomie essentieel is voor ieder die, anders dan alleen t.a.v. bepaalde onderdelen of aspecten, adviserend werkzaam wil zijn m.b.t. algemene organisatievraagstukken. Wat dat betreft verkeert de accountant, dank zij de opleiding welke hij op dit gebied heeft genoten, in een gunstiger positie dan vele anderen die zich tot deze arbeid geroepen voclen 